\title{
On the Credit Alienation and Countermeasures of E-commerce
}

\author{
Jingwei Liu \\ College of Humanities and Social Science, Northeast Forestry University \\ 26 Hexing Road, Xiangfang District, Harbin 150040, China \\ Tel: 86-451-8219-2162Ｅ-mail: dlliujingwei@yahoo.com.cn \\ Jiangxia Yu (Corresponding author) \\ College of Humanities and Social Science, Northeast Forestry University \\ 26 Hexing Road, Xiangfang District, Harbin 150040, China \\ E-mail: yjxd1@live.cn
}

\begin{abstract}
Similar to the global financial crisis in 2008 which is essentially the credit crisis, there are also general problems of distorting, alienating credit or credit evaluation mechanism through widespread speculation of credit, bogus transaction in e-commerce, which has resulted in the deterioration of trading environment. This paper introduces the concept "credit alienation" by the analysis of the financial crisis, mainly takes the credit evaluation of the auction websites in China for example, and analyzes the credit crisis in e-commerce and the root causes in detail. The emphasis is to explore the way to overcome the credit alienation, and build the necessary hardware and software environment for the development of e-commerce.
\end{abstract}

Keywords: E-commerce, Credit alienation, Credit evaluation

\section{The credit and the credit alienation}

As the internal ethical character and the existing basis of the market economy, credit is the will and capacity to combine the psychological commitment and agreed practice on the basis of honesty and trustworthiness, plus the formed and developed code of conducts and rules of transactions. As a result, credit, which connotes various elements such as the need for benefit, the psychological confidence, the agreed form, the required rules, the agreement practicing and the value evaluation (Wang Shuqin, 2005, 7), and includes different forms such as the ethical, legal, and political credit, is essentially the integration of words and deeds, qualitative credit and capital credit, subjective honesty and objective solvency. Credit is not only the foundation of subsistence, but the ground of entrepreneurship. In view of the specialty of the virtual market, the credit in Internet age has become a scarce moral, economic and social resource more important than that of any epoch. E-loyalty is considered to be a key success factor in e-commerce (Marcel Gommans, Krish S. Krishnan \& Katrin B. Scheffold, 2001,43-58). However, as is often to be over-stimulated, exploited and amplified, especially within the context of increasing colonization of economic life, the credit is experiencing a growing commercialization and disorder, and thus leading to the anomaly of the entire credit environment.

The global financial crisis in 2008 was fundamentally resulted from the increasing spread of the credit crisis promoted by the alienation of financial credit. The ideology of financial transactions, which took the concept as the general equivalent, undoubtedly had paved the way for the alienation of the economic credit. Due to the abuse of economic credit, the financial transactions had increasingly evolved into the concept profiteering, and the commodity - credit economy had developed into the finance - concept economy. No matter the excess money during the virtual credit expansion, or the allergic chain reaction in the field of consumer credit and the excessive response after the outbreak of the crisis, were all signs of maladjustment to the dependence, zooming, and alienation of credit in financial civilization. The alienation was far from over, the boom of the economic credit subsequently converted into the crisis of administrative credit and the loss of the political credit. The credit rating agencies, who shared the dual role of the market adjudicator and the responsible stakeholder, not only took the flawed mathematical model as the rating basis, but driven by interests, changed the ratings of debt securities for huge ratings gains, adding fuel to the flames by pushing 
the "toxic debt" into the circulation channels. This rating departing from the fundamental credit deprived of its function of risks revealing and warning, thereby led to the distortion of the credit assessment and the losing control of the credit risk on the micro-level. As the credit rating agencies and the other main bodies, which can perceive the risk of subordinated debt continued to release risk, the alienation constantly escalated and the risk incessantly enlarged as well. The over-intervention of the government, political parties and interest groups, also encouraged the moral hazard, and ultimately made the risk of credit derivatives go beyond the government's control.

\section{The credit alienation in e-commerce}

However, once the credit evaluation for business loses the authenticity and fairness, the trading environment will worsen rapidly, the consumers will become the indirect victims, and the collapse and destruction of trading platform itself will be just around the E-commerce is confronted with varying degrees of credit alienation likewise, especially in the credit evaluation mechanism, although its alienating mechanism is different from the deteriorating and distorting process of the multiple credits in the financial crisis, credit evaluation mechanism is the core path to resolve the credit plight of e-commerce, However, the process of eliminating the credit alienation in such a emerging economic model, may be more difficult and complicated.

As it were, the electronic network triggers a major change of social members' communicative manners ----from "presence" to "absence". In this "strangers society", where space-time weakened and separated, people have to place their hopes and trust in the institutional commitment from such an abstract system, and take a switchover from personal trust to system trust (Gao Zhaoming, 2002, 11). The virtual market's long range, record alterability and the complexity of subjects, make its credit issues more prominent than the physical market; the trading environment's virtuality and non-contacting feature, as well as the corresponding changes in the way of credit accumulation, subverts the " scheduled harmony" in traditional ethical world, and reveals the straitness of human relationships, bringing the online transactions, particularly the one-off game the potential safety hazard. Therefore, this distinctiveness of e-commerce no doubt offers an enlarging space to the economic rational man's pursuit of the maximizing economic interests. The commercialization of human relationships, the honesty-losing consumption patterns, further decreases people's confidence in the credit mechanism, and provides more opportunities for the discreditable behaviors. In short, the innate, potential safety hazard and acquired systematic, technical loopholes, plus the profit-pursuing activities in the real world, provide the hotbed for the alienation of credit; the so-called declaration "credit first" actually often inverts into the distortion of credit and the speculation of the false credit, but can not be the true admiration for credit, let alone the accumulation of the credit.

Take the credit evaluation of the auction websites in China for example. In view that establishing the credit system of the virtual market is the main path to solve the credit problems in the virtual markets, the credit evaluation, which informationizes the credit quality, and provides an important source of trust for the credit in abstract system, has become the key to build this system. The purpose of the credit evaluation is, according to the past trading information, to determine the quality of the products or services delivered by the seller, as well as the buyers' behaviors in paying the purchase price. Hence, it is the value label or trademark characterized the overall quality of individuals or enterprises.

However, there are still a series of problems involved in current credit evaluation of e-commerce: the unsound laws and regulations on credit management, the prevalent division and asymmetry of credit information, the ambiguous and one-sided certification system, the overly simplistic trust model, and the non-uniform credit rating, and so on. In the backdrop of highlighting "ecological crisis of network ", lots of stakeholders take credit as virtual goods, through malicious speculation, to make disguised self-packaging and increase the credit accumulation, which not only deteriorate the trading environment of e-commerce, but also exacerbate the imbalance of the demand and supply of the credit in e-business. The alienation of the credit evaluation mechanism, which aims to avoid the "Prisoner's Dilemma" and clear up the anonymous risk, will inevitably reduce the consumers' confidence and identity in e-commerce, accelerate the escalation of the credit crisis, thereby leave hidden dangers for the so-called "bubble economy".

The credit alienation in the credit evaluation of auction website mainly refers to the commercialization and instrumentalist of credit. In order to improve their credit rating quickly, lots of e-commerce websites resort to every conceivable means to engage in credit speculation, from the sale of the assessment, to the exchange of the false assessment and the purchase of the assessment; from the websites' own low-level speculation, to the senior speculation in the form of "seller collusion". The appearance of the "occupational hand brushes", through the abnormal application of the rules, directly distorts and alienates the credit into a kind of virtual goods. However, once the credit evaluation for business loses the authenticity and fairness, the trading environment will worsen rapidly, the consumers will become the indirect victims, and the collapse and destruction of trading platform itself will be just around the corner. Commodities trading platform established on the basis of the credit, finally alienated the credit into commodity.

Currently, there is no two-way credit evaluation system between the individual consumer and the credit rating agency for e-commerce yet, and the certification system the websites adopt is only oriented to the buyers rather than the sellers. Consequently, to seek higher interests of the e-transactions, many individual consumers also take the false transactions 
or the "buyer collusion" to improve the credit rating in existing e-commerce system, which not only do great damage to the interests of other individual consumers who conforms the real transactions, but further reduce the fairness of the e-commerce credit rating. As the simple credit evaluation model doesn't involve the factors such as the scoring weight, transaction price, and the confidence level of the appraiser, it can not encourage users to adopt the long-term integrity trading strategies, and reveals the confidentiality risks of the potential trading partners fundamentally, but instigates the endless opportunism instead. Many opportunists, after using the low-value commodities to obtain a high credit rating and credit quality, then begin to abuse credit rating and lose his trust in the transactions of high-value goods to obtain illicit higher earnings. Some others take the credit ratings as retaliatory tools, and do malicious evaluation irresponsibly.

As pointed out by Shoaf and Sama, ethical rationale in the New Media is largely non-existent; ethics and e-commerce is an oxymoron, because e-commerce is in a state of anarchy, and its internally organizational culture shows a weak ethical climate specifically, that is, a low moral intensity (LM Sama \& V. Shoaf, 2002, 93-103). In that case, in such a digital world "lack of the World of Ethics" (Fan Hao, 2007, 80), and full of false cultural consciousness, how to do a good self-adjustment and self-transformation, to return the true face of the commercial credit? What course should e-commerce follow?

\section{The e-commerce in opportunities}

With the globalized, standardized, high-speeding and low-cost mode of doing business, e-commerce can serve as a strong driving force for the economic globalization. Nevertheless, this new business form doesn't promote rapidly as expected in many countries. And on the whole, it experienced a process from the initial optimism and frenzy chasing to calm analysis and earnest summary. Obviously, credit is one of the most important stumbling blocks.

The universal predicament of traditional enterprises always pushes the new economic model to the ahead of market, and the financial crisis caused by the credit alienation demonstrates the potential advantages and broad prospects of e-commerce powerfully. In the grim circumstances of funds lacking and cost inflation, the medium-sized and small enterprises have no option but to re-consider the input and output ratio, and seek the new marketing concepts, tools and methods to ease the cost pressures of transactions maximally. E-commerce has thereby become the best choice for the business to increase income and decrease expenditure, and adjust the strategy, to turn the passiveness into the initiative, and the crisis into the opportunities. On the other hand, the crisis also prompted many netizens to choose the cost-effective e-commerce to reduce the consumption cost. Facing the opportunities in the crisis, the e-commerce industry, which has the same serious potential credit issues, should enhance the crisis consciousness, seek for the root causes of the crisis multi-dimensionally with systematic thinking, and by means of social, legal and technical strategies, to build a strong, stable credit system, ensuring the well operation of the credit system.

In the long run, through the joint efforts of the government, individuals and society, foster the credit culture upon which the modern credit system depend for survival, and realize the transformation from the over-reliance on human relations to the true admiration for the modern contracted culture, is our endeavoring direction and macro objective. Credit culture is a kind of social capital necessity for a sound credit system, which is crucial to the building of the market economy's moral basis, even the construction of the whole social credit.

However, China's current credit culture has become increasingly the constraints to the innovation of credit system. For one thing, the traditional credit culture is on the decline in contemporary society, which has resulted in unprecedented social credit crisis, and the confidential inertia is also difficult to be developed; for another, the undue dependence of the market credit system on the human relations, confuses frequently the credit ratings and the adjusting methods of the market credit system with the ones in human relations.

Therefore, in the virtual market filled with moral realistic culture, it is necessary to take the moral rationalism in the cultivation of credit culture and network moral, and intensify people's credit consciousness via the development of the formal credit system. That is to say, in the sustained efforts to enhance the trust in the virtual system and create the favorable moral atmosphere of network through education and advocacy, not limit to the traditional moral discourse, but stress more the perspective of economic rationality, and give the stakeholders positive reinforcement or reverse stimulation by economic means. With the effective cooperation with the legal system, the linkage mechanism where the ethical credit and system credit, the "soft constraints" and the "hard constraints" combine and promote each other will take shape gradually, and in turn advancing the accumulation of credit capital and optimize the credit environment of e-commerce.

Ethical credit is the effective value support and basic resources for the successful market transactions. As a result, we must conduct a more in-depth research of network ethics, and explore the concrete, effective practicing forms to enhance the construction of the e-business ethics and values, make "the awareness of network ethics" embed in the public gradually, and internalize the related responsibility for the conscious activities of interest subjects. Only when the necessary network ethics and ethical identity for the promotion of e-business is created and nurtured, can we achieve the unity and integration of the instrumental rationality and the value rationality in credit ethics, and then truly improve and 
optimize the quality of the network life and the state of the co-existence.

Of course, as an informal system, which is the outcome of long-term accumulation of historical experience, the social trust cannot be obtained through rational economic investment or the other shortcuts in short period. The improvement of institutions or technologies, which constitute the skeletons of social credit system, however, is often in a better position to produce instant results. Furthermore, the access to the concept of credit has to go through a process of the external rules transforming into the internal initiative and moral conscience. In addition, it is also the important experience of developed countries that the establishment of a credit system must put the legislation and technological updating the first place. Despite that the three major US rating agencies have suffered the global attack as a result of the scandal of discredit in the financial crisis, but it can not be denied that by virtue of sound credit laws and special credit agency, as well as the long-term accumulation of legal credit culture, the United States has been able to provide the effective guarantee and supervision to the credit of the businesses or individuals participating in e-commerce, and ultimately boost the prosperity of e-commerce. As a consequence, it is essential to accelerate the construction of the credit system, particularly the improvement of the credit evaluation system.

First of all, cultivate the professional, independent and impartial e-business credit-assessment agencies. Through market operating, use the information technology to carry out the dynamic collection, processing and evaluation of the business or personal credit information, promoting information sharing and ensuring the consistency of the evaluation standards. At the same time, strengthen self-discipline, set up and perfect the credit alliance among the business websites, and carry out the activities like the credibility forum, to achieve the interconnection of the credit resources and self-supervision among different websites, resolving the problem of " the solitary Island of credit " resulting from the information division as far as possible. In the developing economies where the market economy has not yet fully developed, and the social credit are still in disorder, the completion and operation of these authorities is especially important to the development of e-commerce. In addition, while developing and applying continually the techniques of on-line security certification, the government should organize or authorize the public sectors responsible for the verification and supervision of authentication, further enhancing the fairness of the credit evaluation in e-business.

Secondly, institute and improve the credit evaluation system. Select and design the scientific, integrative, comparable, practical and dynamic credit evaluation, ensuring the results of credit evaluation are objective, fair and reasonable; elaborate the criteria of credit evaluation, set "the classified credit system with variable weight " adhering to the combination of the qualitative analysis and quantitative analysis, and give full consideration to transaction times, trading volume and the impact of the original credit quality; establish a strict reward and punishment mechanism of credit, where the range of punishment is greater than the ones of incentives, to increase the cost of dishonest conducts; implement the incentive mechanism of the credit evaluation, encouraging the individuals and enterprises to participate in on-line credit ratings. As China still lacks a set of authorized personal credit scoring procedures and the corresponding scoring model, which has experienced the scientific design, rigorous argument, and can come into play quickly, it is difficult to ensure the standardization, fairness and share of the credit assessment of e-commerce. For this reason, it is imperative for the government to formulate the standards of the credit rating and improve the credit evaluation system as soon as possible, eventually taking the credit evaluation of e-commerce into the construction of China's social credit system.

Thirdly, promote and perfect the credit management system. As has been stated, the healthy legal environment and well-developed legal credit play a pivotal role in the e-commerce credit evaluation, or even the credit-building of the whole e-business. Unfortunately, China has not yet formed a set of complete e-commerce legal system to restrain the conduct of e-transactions at present. The absence of the law and the lagging credit evaluation mechanism, are bound to raise the negligence to the defense of credit and cause the weightlessness of the credit in the benefits balance. Therefore, on the basis of the combination of localization and internationalization, given full consideration to the characteristics of e-transactions, the forward-looking laws and regulations must be established as soon as possible. On one side, determine the rules of the game and institutional reference system, making the credit activities such as the information opening, rating, application and publication, have regulations to abide by; on the other side, play the role of the legal system in shaping and strengthening ethical credit and credit culture, and ultimately realize the joint development of the ethical credit, economic credit and legal credit, providing the necessary soft and hard environment for the development of e-business.

\section{References}

Fan, Hao. (2007). The World of Ethics in the Electronic Information Mode. Social Sciences in China, (2), 80.

Forecast Think Tank. (2008). Why the global credit crisis was enlarged. [Online] Available: http://www.jfdaily.com/gb/jfxww/xlbk/node22032/node43464/node43477/userobject1ai1975032.html (Dec 7, 2008)

Gao, Zhaoming. (2002). The Modern Interpretation of the Credit Crisis. Academic research, (4), 11.

LM Sama \& V. Shoaf. (2002). Ethics on the Web: Applying moral decision-making to the new media. Journal of 
Business Ethics, 36(1-2), 93-103.

Marcel Gommans, Krish S. Krishnan \& Katrin B. Scheffold. (2001). From Brand Loyalty to E-Loyalty: A Conceptual Framework. Journal of Economic and Social Research, 3(1), 43-58.

Wang, Shuqin. (2005). The Research of Credit Ethics. Beijing: Central Compilation \& Translation Press, 7. 